\title{
A new EMPIR Project "MetForTC" for Developing Traceable Measurement Capabilities for Monitoring Thermocouple Performance
}

\author{
Narcisa Arifovic ${ }^{1, *}$, Danijel Sestan ${ }^{2}$, Davor Zvizdic ${ }^{2}$, Nedzadeta Hozic $^{3}$, Emese Turzo- \\ Andras $^{4}$, Semir Cohodarevic ${ }^{3}$, Radek Strnad ${ }^{5}$, Karsten Opel $^{6}$, Dimitru Neagu ${ }^{7}$, Constantin \\ Bordianu $^{8}$, Snezana Spasova ${ }^{9}$, and Tanja Vukicevic $^{10}$
}

\footnotetext{
${ }^{1}$ TUBITAK-UME, Turkiye Bilimsel ve Teknolojik Arastirma Kurumu, Gebze Yerleşkesi, Turkey

${ }^{2}$ FSB, Fakultet strojarstva i brodogradnje, Ulica Ivana Lučića 5, 10000, Zagreb, Croatia

${ }^{3}$ IMBIH, Institut za mjeriteljstvo Bosne i Hercegovine, Augusta Brauna br.2, 71000 Sarajevo, Bosnia and Herzegovinia

${ }^{4}$ BFKH, Budapest Főváros Kormányhivatala, Németvölgyi út 37-39, 1534 Budapest, Hungary

${ }^{5}$ CMI, Cesky Metrologicky Institut, Okružní 31, 63800 Brno, Czech Republic

${ }^{6}$ JV, Justervesenet, Norwegian Metrology Service, Fetveien 99, 2007 Kjeller, Norway

${ }^{7}$ BRML, Biroul Roman de Metrologie Legala, Sos. Vitan Barzesti 11, Sector 4, 042122, Bucuresti, Romania

${ }^{8}$ INM, Institutul Naţional de Metrologie, Eugen Coca street 28, 2064 Chisinau, Moldova

${ }^{9}$ BIM, Bulgarian Institute of Metrology, 52B, G.M. Dimitrov blvd., 1040 Sofia, Bulgaria

${ }^{10}$ MER, Zavod za metrologiju, Arsenija Boljevića bb, 81000 Podgorica, Montenegro
}

\begin{abstract}
In order to enhance the availability of facilities in the field of contact thermometry in European emerging National Metrology Institutes (NMIs) and Designated Institutes (DIs), where access to types of facilities is currently limited an EMPIR Research Potential Project named "Traceable Measurement Capabilities for Monitoring Thermocouple Performance" (MetForTC) has been launched. Overall ten partners has been involved in the project, five of them participating from the emerging countries. This project will develop skills and tools for less experienced NMIs/DIs in order to acquire the required knowledge and expertise in temperature metrology. The MetForTC Project has been addressing the accurate low uncertainty temperature measurements by thermocouple which is of crucial importance for ensuring better manage of the metrological features of the thermal instrumentation used for realizing of temperature measurements as well as to construct a comprehensive approach for the uncertainty budget assessment. Special emphases has been given on novel practical methods and technical capabilities for checking the thermocouple's drift performance
\end{abstract}

\footnotetext{
* Corresponding author: narcisa.arifovic@tubitak.gov.tr
} 
in-situ and easy-to-use thermocouple with integrated miniature cells required to determine the inhomogeneity of thermocouples for primary and secondary calibration laboratory.

\section{Introduction}

This paper deals with the new EMPIR Project MetForTC that has been launched in June 2019. [1] The general aim of this project is to develop novel scientific and technical capabilities for improving the metrological infrastructures in European NMIs/DIs, in temperature field.

This project focuses on emerging NMIs/DIs that recognize the need to develop a research potential in measurement techniques, facilities and expertise in this area. The traceability chain for any temperature sensor is established from NMIs to industries via different levels of calibrations. There is a need to complete, upgrade and implement regional metrological infrastructure in the field of temperature measurements in the beneficiary countries and to manage the metrological features and the traceability of thermocouples.

\section{The quality and efficiency of the implementation}

In total, 10 NMIs/DIs (TÜBİTAK-UME-Turkey, FSB -Croatia, BFKH-Hungary, IMBiHBosnia \& Herzegovina, CMI-Czech Republic, BIM-Bulgaria, BRML-Romania, JV-Norway, INM-Moldova, MER-Montenegro) are included within this project.

The leading NMIs/DIs of the consortium (TUBITAK, FSB, BKHF, CMI and JV) have significant experience and excellence in the area of temperature measurements and research. On the other side, the emerging NMIs/DIs have adequate equipment to carry out the project but limited experience and existing capabilities, particularly in temperature related research. Collaboration between those partners that are less experienced in research (IMBiH, INM, BRML, BIM and MER) and those that are more experienced and developed will develop the former's metrology capabilities and infrastructure for traceable temperature measurements, which will support their participation in future research projects. The research objective is to transfer scientific and technical knowledge from the leading NMIs, to the laboratories which are developing their own metrological infrastructure.

\section{Research Highlights}

The thermocouple performance is critically dependent upon uniformity of physical and chemical properties along the length of the thermoelement. With use, thermocouple lose homogeneity through heat, chemical exposure, or mechanical damage causing measured voltage to differ at the same temperature, resulting in error and reducing severely the temperature measurement accuracy.[2,3,4]

For high precision calibration, primary and secondary calibration laboratories are required to determine the inhomogeneity of thermocouples while performing their calibrations. Unfortunately, standardized, easy-to-use methods and devices are not currently available for the task. At the level of primary laboratories, new and extended traceable measurement methods and devices that will provide confidence in the verification of thermocouple performance are needed.

The objective of the research is to develop novel methods and techniques that will significantly improve knowledge and facilities for the verification of thermocouple performance for primary and secondary calibration laboratories. 
The specific objectives are:

- To develop and test novel methods and devices for the monitoring of thermocouple drift in-situ in the temperature range up to $1100{ }^{\circ} \mathrm{C}$.

- To develop and test easy-to-operate methods and instruments for the assessment of inhomogeneity of thermocouples for secondary calibration laboratories in the temperature range from $230{ }^{\circ} \mathrm{C}$ to $1100{ }^{\circ} \mathrm{C}$.

- To design and construct novel measurement facilities that can provide confidence in the verification of thermocouple performance and to identify and quantify the range of drift of the thermocouples. The new facilities, targeting primary calibration laboratories, should have the ability to measure the physical changes and behavior of thermocouples under typical conditions of production and distribution processes with a target uncertainty of less than $1.5^{\circ} \mathrm{C}$.

\section{Scientific and Technical Excellence}

The voltage generated by a thermocouple at a particular temperature changes over time and this phenomenon is called a drift. It is basically a departure of the voltage-temperature relationship from the one determined during the previous calibration, or a rapid excursion from the manufacturer's tolerances. The rate of drift is essentially impossible to predict.[5,6] For industrial users drift causes many problems, such as higher energy costs, loss of time due to process disruption (to replace or recalibrate the failed thermocouples) which usually involves shutting down the processes and waste of product when measuring errors become too large. The work on the proposed topic in WP1 will develop novel practical devices and methods for checking the thermocouple's performance in-situ using, for example, dual-type thermometers and heaters array, thus enabling users to determine the thermocouple departure from specified tolerance limits in a fast and accurate way. In this way, the costs of precautionary (too early) replacements of thermocouples will be avoided. At the same time, bad performing thermocouple could be detected sooner than low accuracy measurements cause harm or wastes in production or service.

The work in WP2 will develop easy-to-use methods and devices required to determine the inhomogeneity of thermocouples performance for secondary calibration laboratory. [7, 8] WP3 extends the activities in WP2 and aims to improve the experimental characterization of drift and inhomogeneity of thermocouples on the primary level. The setup optimized for control of the position and the heat input to the thermocouple and longer lasting fixed-point plateau, will enable a better determination of the inhomogeneity and a reduction in the uncertainty of thermocouples through mitigating drift and homogeneity effects. [9] The target uncertainty will be less than $1,5^{\circ} \mathrm{C}$ up to $1100^{\circ} \mathrm{C}$.

Moreover, WP3 will develop and validate theoretical and numerical analysis based on performance checks of the thermocouples and to determine the potential sources of measurement uncertainty for these instruments.

\section{Industrial Impacts}

This Project will allow a contribution to creating impact via dissemination of research outputs to end-users through conferences, papers, guidelines, etc. 
In general, the knowledge gathered in this Project will help the partners from emerging countries to further develop their capabilities in designing and building new measurement equipment. This will meet the demand of industry to obtain high-accuracy calibration services in Europe, while making calibrations less time consuming and less expensive. Further, due to the need of end users to select appropriate products and make informed decisions related to performance and cost, and due to the need of manufacturers and distributors to meet regulatory requirements, it is necessary that reliable information on the properties of thermocouples is available. In addition to this, users of thermocouples need information on their measurement uncertainty, where the level of drift and changes in homogeneity of thermocouple wires has significant influence. Therefore, appropriate methodology for testing these effects on the accuracy of temperature measurements using thermocouples needs to be developed and validated.

Another important characteristic of this project is to develop scientific and technical capabilities in thermal measurement in a number of European countries that currently have limited metrology capacity (beneficiary partner countries). The partners will work together developing and thus homogenizing their competence and capacity. TUBITAK, FSB, BFKH, $\mathrm{CMI}$ and JV will share their existing knowledge and expertise among consortium members and will work in strong linkage together with IMBiH, INM, BRML, BIM and MER on the development, construction and characterisation of platinum based thermocouples and miniature fixed points that will provide reliable calibration capabilities for thermocouple calibrations.

\section{Conclusions - Perspectives}

The aims, objectives and highlights of the new EMPIR Project MetForTC has been outlined. The project will develop novel methods and techniques, traceable to the ITS-90, that will significantly improve knowledge on drift and homogeneity as well as confidence in the verification of thermocouple performance for primary and secondary calibration laboratories. Eventually it will lead to the decrease in the uncertainty of the measurement of temperature by thermocouple and, as a result, the efficiency of the industrial processes will be increased.

\section{Acknowledgements}

The work $\begin{aligned} & \text { presented } \\ & \text { Metrology here is }\end{aligned}$ Programme
European
and Research (EMPIR). EMPIR is jointly funded by the EMPIR participating countries
within EURAMET and the European Union.




\section{References}

1. N.Arifović \& al, JRP Proposal, 18RPT04, "Traceable Measurement Capabilities for Monitoring Thermocouple Performance“, MetForTC, version Date: (15 May 2019).

2. D. Zvizdić, T. Veliki, "Testing of Thermocouples for inhomogeneity“, IMEKO World Congress, Rio de Janeiro : 1-6.LETRA CAPITAL Editora (2006).

3. F. Jahan and M.Ballico, "A Study of the Temperature Dependence of Inhomogeneity in Platinum-Based Thermocouples", National Measurement Laboratory, CSIRO, Australia

4. R.E.Bentley, "A thermoelectric scanning facility for the study of elemental thermocouples", CSIRO National Measurement Laboratory, Sydney 2070, Australia

5. P. Pavlasek, R. Strnad, A. Blahut, M. Jelínek, G. Failleau, M. Sadli, N. Arifović, A. Diril, M. Langley, J.V. Pearce, "Procedure for an investigation of Drift behaviour of Noble Metal Thermocouples at High Temperature" (2014)

6. G. Failleau, N. Arifović, T. Deuzé, A. Diril, S. Duris, C.J. Elliott, M. Langley, P. Pavlasek, J.V. Pearce, M. Sadli, R. Strnad, "Investigation of the Drift of a Batch of Base Metal Thermocouples at High Temperature", TEMPMEKO 2013

7. M.Kalemci, N.Arifović, A.Bağçe, S.O.Aytekin and A.T.Ince, "Construction of homemade tin fixed point cell at TUBITAK UME”, Int J Thermophys 36:1968-1979 (2015)

8. D. Zvizdić, D. Šestan, “Tin-Filled Multi-Entrance Fixed Point", Temperature: Its Measurement and Control in Science and Industry, Volume 8 / Proceedings of the Ninth International Temperature Symposium, 259-264Melville, New York:AIP Publishing, (2013).

9. T. Nemeth, S. Nemeth, E. Turzo-Andras, "Experimental study of the phase transitions of different fixed points“, Int. J. Thermophys, 36:8: 1968-1979 (2015) 